\title{
High Grade B-Cell Lymphoma with MYC, BCL2, and BCL6 Rearrangements
}

National Cancer Institute

\section{Source}

National Cancer Institute. High Grade B-Cell Lymphoma with MYC, BCL2, and BCL6

Rearrangements. NCl Thesaurus. Code C131913.

A rare B-cell non-Hodgkin lymphoma that is characterized by the abnormal

rearrangement of MYC gene, BCL2 gene, and BCL6 gene. Patients with this type of

lymphoma usually respond poorly to standard treatments and have a poor prognosis. 